University of Nebraska - Lincoln

DigitalCommons@University of Nebraska - Lincoln

Congreso internacional sobre iconografía

precolombina, Barcelona 2019. Actas.

8-20-2020

\title{
Vida y Sacrificio: Los nueve rituales para la luz la vida y el maíz
}

Marina Valls i García

Follow this and additional works at: https://digitalcommons.unl.edu/actas2019

Part of the American Material Culture Commons, Indigenous Studies Commons, Museum Studies Commons, Other History of Art, Architecture, and Archaeology Commons, and the Other Languages, Societies, and Cultures Commons

This Article is brought to you for free and open access by the Zea E-Books at DigitalCommons@University of Nebraska - Lincoln. It has been accepted for inclusion in Congreso internacional sobre iconografía precolombina, Barcelona 2019. Actas. by an authorized administrator of DigitalCommons@University of Nebraska - Lincoln. 


\title{
Vida y Sacrificio: Los nueve rituales para la luz la vida y el maíz
}

\author{
Marina Valls i García \\ Grup d'Estudis Precolombins (GEP), Universitat Autònoma de Barcelona \\ marina.vallsg@e-campus.uab.cat
}

\begin{abstract}
Resumen
El Códice Borgia presenta uno de los rituales más complejos de toda la liturgia mesoamericana; el conocido como "los nueve rituales para la luz, la vida y el maíz". El presente estudio es la primera entrega de una serie de artículos en los que se realiza una revisión crítica e interpretativa del ceremonial litúrgico, representado entre las páginas 29 y 42 del documento. Con el objetivo de una mejor comprensión de todo el imaginario reflejado, se plantea una aproximación interdisciplinar que permita apreciar la gran cantidad de figuras poéticas visuales y sutilezas que conforman el discurso religioso y artístico mesoamericano, aspirando a una mayor intelección de su cosmovisión.
\end{abstract}

Palabras clave: Códice Borgia, religión, rituales, liturgia, cosmovisión, sacrificio humano

\begin{abstract}
The Borgia Codex presents one of the most complex rituals in all the Mesoamerican liturgy; the known as "the nine rituals for light, life and corn". The present work is the opening article of a series in which the ceremonial represented, between the pages 29 and 42 of the codex, is critically revised and analysed. With the main aim of a better comprehension of the whole reflected imaginary, an interdisciplinary approach allows us to realize the large amount of rhetorical figures and subtleties englobed in Mesoamerican religious and artistic speeches and, hence, a finer understanding of their worldview.
\end{abstract}

Keywords: Borgia Codex, religion, ritual, liturgy, worldview, human sacrifice
El Códice Borgia $\left(\mathrm{CB}^{1}\right)$, es un documento único en su especie; aunque no es el único códice de carácter divinatorio-ritual sí que presenta ciertas características insólitas, como las escenas de la parte central del códice comprendidas entre las páginas 29 y 46 del CB. La excepcionalidad de estas páginas y su naturaleza enigmática ha hecho que los académicos lleven más de un siglo intentando vislumbrar el verdadero significado de unas páginas en las que nada parece haber sido incluido al azar. Sin embargo, dada la complejidad de estas imágenes, aún no parece haber un consenso determinante para la interpretación del códice 2 . Por ello, este estudio pretende aportar algunas nuevas consideraciones que permitan corroborar y/o desmentir las teorías anteriores mediante una revisión crítica basada en los métodos propios de la historia del arte, como el análisis compositivo o el análisis iconográfico e iconológico más allá de la identificación de personajes y sus atributos.

Los primeros estudios publicados sobre el CB (Seler, 1906 y 1963) asumieron que se trataba de un documento que recogía distintos mitos relativos a la cosmología y la astrología de los antiguos pueblos de México. Sin embargo, aunque se partiera de una interpretación aparentemente elocuente, más tarde imagen y mito divergían de

1 Todas las láminas del CB se encuentran al final del artículo, identificadas con el número de página original que ocupan en el códice, consultar a necesidad del lector.

2 Consultar la bibliografía específica para ver el listado de los principales estudios interpretativos del códice.

Publicado en Congreso internacional sobre iconografía precolombina, Barcelona 2019. Actas, Victòria Solanilla Demestre, editora (Lincoln, Nebraska: Zea Books, 2020). https://doi.org/10.32873/unl.dc.zea.1245 
manera irreconciliable, obligando a realizar lecturas forzadas de imagen. Un claro ejemplo de ello es el comentario que hace Seler de la primera página del ritual (29 $\mathrm{CB}^{3}$ ), la cual interpreta como el mito tolteca de Quetzalcoatl convirtiéndose en Venus. Seler legitima su tesis a través de la repetida aparición de Quetzalcoatl en las láminas y los accesorios iconográficos que presenta el personaje -el tocado de estrella y la pintura facial ${ }^{4}$ - que relaciona con Venus. Asimismo la continuidad narrativa del documento lleva a Seler a pensar que se trata del viaje de Venus por el inframundo, es decir que se estaría plasmando el período de conjunción superior del ciclo de Venus, cuando el planeta queda oculto detrás del sol para más tarde reaparecer como Estrella Vespertina. Aún y aceptando la premisa de que realmente se está representando este episodio, cuando Milbrath (1989) intenta cuadrar el ciclo de Venus con los días señalados en las páginas del Borgia observa que aunque los días no encajan con el ciclo de Venus el ritual consta de 18 láminas, e intenta relacionar cada página con un mes del Xiuhpohualli, calendario agrícola de 18 meses. No obstante las 8 primeras páginas del CB se dedican a la representación del Tonalpohualli, calendario ritual dividido en 20 semanas de 13 días. Resulta cuanto menos extraño que habiendo representado un calendario divinatorio-ritual las escenas a continuación utilizen otra unidad de medida del tiempo. Sin embargo, la secuencia de días señalados en estas escenas del CB sigue siendo un tema controvertido, dado que hasta la fecha nadie ha logrado descifrar de manera completa como interactúa la actividad con el factor tiempo. Con todo, cabe decir que ambos estudios contribuyeron no solo a generar interés académico por el documento sino que fueron las primeras publicaciones en las que se hizo un ejercicio de identificación de personajes y elementos, que han servido al resto de la historiografía para desarrollar otras teorías e interpretaciones.

Por otro lado encontramos a Nowotny $(1961,1976$ y 2005), el primero en valorar la posibilidad de que lo representado aquí no sea la plasmación de un mito sino de un ritual. Más concretamente de 14 rituales independientes unos de otros pero todos ellos vinculados a un mismo espacio ceremonial concreto. La idea resulta cuando menos interesante, ya que eso implica que éste documento podría ser algo así como un manual litúrgico de un centro ceremonial concreto. Una de las principales críticas a Nowotny es que ninguno de los cronistas pareció registrar el ritual, pero sería ridículo limitar toda la actividad litúrgica mesoamericana a solamente aquellas prácticas que sí fueron documentadas obviando otras tantas que quizá no tuvieron la oportunidad de ver o que simplemente se han perdido por el camino.

Más tarde Anders, Jansen y Reyes García (1993) publicaron uno de los estudios más extensos sobre la totalidad del CB en el que recogían los estudios de Nowtony. Al contrario que su maestro que afirmaba que se trataban de rituales independientes entre sí, Anders, Jansen y Reyes García entienden las 18 páginas como una unidad en sí misma - una acción dividida en 9 fases pero con un fin común; la aparición y el nacimiento de la luz la vida y el maíz partiendo de la oscuridad, el tumulto y la muerte. Por otro lado, sí coinciden en la idea de que se trate de un ritual íntimamente ligado a un espacio ceremonial concreto, incluso acaban "reconstruyendo" de modo esquemático todo el complejo religioso donde la acción tendría lugar (Anders, Jansen y Reyes García, 1993: 182).

Coetáneamente Byland (1993) publicó su investigación en la que argumentaba que esas escenas estaban representando un ritual de ascenso al trono. Basa su teoría en la alusión a la ceremonia de apertura de ojos, un ritual de carácter político que se practicaba a modo de rito de paso o ascenso al poder en la que el sacerdote mayor "rasgaba" los ojos del sujeto con un cuchillo de pedernal para hacer que éste "naciera" en su nuevo cargo o estatus. Sin embargo ésta interpretación carece de suficientes nexos con las escenas representadas por el mismo motivo que fallaba la interpretación de Seler y Milbrath; aunque haya algún punto de encuentro grande entre la teoría y alguna escena del ritual hay otras muchas acciones representadas que divergen totalmente de la narrativa propuesta y eso suele ser una señal de que la lectura probablemente no sea la pertinente.

Volviendo a la concepción de las láminas centrales como un mismo ritual con diferentes escenas pero con una narrativa común encontramos los estudios de Boone (2007) y Batalla Rosado (2008), quienes recogen todo el imaginario que anteriormente se ha relacionado con el documento y lo revisan concluyendo que se trata de un ritual vinculado con los mitos de creación. Sin embargo ambos defienden interpretaciones muy distintas. Para Batalla Rosado se está representando el viaje del sol por los nueve niveles del inframundo durante la noche, para él se trata de un ritual íntimamente relacionado

3 Abreviatura para situar al lector en las láminas del CB; página 29 del Códice Borgia.

4 Me refiero a la pintura facial del personaje identificado como ojo rayado o "stripe eye”, del que hablaré más adelante. 
con la muerte y por tanto con Mictlantecuhtli, debido a las constantes referencias a la muerte y la oscuridad. Las páginas para él son «a pictorical reflection of hallucinations that the author(s) had to reach to exercise his priestly office» (Batalla Rosado, 2008; 412). Asimismo defiende que los sacerdotes mesoamericanos ya sabían lo que tenían que hacer y que por ello no necesitaban ningún tipo de manual litúrgico, argumento algo ingenuo teniendo en cuenta el gran corpus litúrgico mesoamericano y dada la gran extensión del territorio mesoamericano - recordando que a mayor extensión de territorio más fácil es que los rituales evolucionen a versiones autóctonas, como ocurre con las lenguas y sus dialectos.

Por otro lado Boone aborda el estudio interpretativo del códice desde el análisis de la estructura gráfica para ver cómo están organizadas las páginas y así poder establecer posibles relaciones o similitudes entre ellas. Como Anders, Jansen y Reyes García participa de la idea que se trata de una sola narrativa dividida en escenas. Sin embargo duda del lazo entre documento y lugar sacro, dando más importancia al significado reflexivo de las imágenes e incluso llegando a sospesar la posibilidad de que se trate de una representación metafórica; «we are dealing with a world of metaphor, where the dark ball court may be less a structure physically located in a particular site than a playing ground for supernatural or cosmic battles» (Boone, 2007: 178) - pese a estar de acuerdo con esta dimensión reflexiva e introspectiva del documento no se puede ignorar que se trata de una representación extremadamente detallada en todos los atuendos, los objetos, la disposición, los pasos a seguir, la configuración y naturaleza de los sitios donde ocurre la acción y hasta la actitud de los personajes que aparecen, algo que solo se justificaría en caso de que el documento pretendiera dar una serie de directrices ceremoniales. Boone coteja todo el ritual con las teorías anteriores y busca establecer nuevas relaciones con los mitos y leyendas de creación mesoamericanos, ofreciendo una nueva lectura que, por ahora, es la que mejor encaja con las escenas representadas en el códice.

Por ello el propósito de éste estudio es repasar las 18 páginas rituales del $\mathrm{CB}^{5} \mathrm{y}$ realizar un análisis compositivo a partir del que se establezcan nuevas relaciones entre el imaginario representado, la cosmovisión y mitología mesoamericana, haciendo especial hincapié en todos los relatos de creación del universo. También se ha buscado una visión interdisciplinar en la que poder construir un discurso completo y cohesionado que permita una mayor comprensión del ritual y por ende de la cultura mesoamericana. ${ }^{6}$

\section{Rito 1}

«Estamos al principio de una era y todo está en tinieblas» (Graulich, 2006: 72). Así empieza la "Leyenda de los Soles", uno de los numerosos mitos de creación mesoamericanos que parten de la oscuridad, la inestabilidad y el tumulto en representación del caos, como amenaza al status quo. Eso mismo es lo que se representa en la página 29 del CB, un recordatorio amenazante del caos que reinaba antes de que los dioses impusieran el orden y crearan el mundo tal y como lo conocemos (Boone, 2007: 179). Todo esto se sintetiza y enfatiza visualmente con la presencia de dos elementos: la llamada "rueda negra de conjuros" y la presencia de Yohualli Ehécatl, una advocación de Tezcatlipoca relacionada con los vientos nocturnos y a la que se solía acudir en momentos de miseria, sequias, etcétera con el fin de lograr un "cambio de aires" (Baena, 2014: 205). Estos surgen de la "explosión" de energía que emerge del "Gran Brasero Azul" o Chalchiuhxicalli cuando Mictlantecuhtli ${ }^{7}$ realiza su sacrificio con la soga de penitencia. Ambos personajes -brasero y dios- aparecen emulando la posición de parto que también veremos más adelante, hecho simbólico que evoca la idea del nacimiento de una nueva era, lo cual reivindica la importancia del Sacrificio ritual, ya que sin él no podríamos dar paso a un nuevo tiempo. Además, si nos fijamos en el esquema compositivo, lo que se estă mostrando es una redonda inscrita en un cuadrado; es decir el microcosmos dentro del macrocosmos, una idea recurrente en la cosmovisión mesoamericana, que en este caso enfatiza el carácter global inherente a Yohualli Ehécatl ${ }^{8} \mathrm{y}$ por extensión al Ritual.

5 El presente articulo es el primero de una serie de dos articulos en los que abordo la totalidad del ritual. En éste se abarca el analisis de la página 29 del CB hasta la 38, dejando las láminas de la 39 a la 46 para la siguiente publicación.

6 En caso que se quiera ahondar en la identificiación de todos los personajes recomiendo consultar el análisis publicado en Boone, 2007: 178-185 (Rito 1); 185-195 (Rito 2).

7 También identificado como el dios Venus muerto (Anders, Jansen y Reyes García, 1993; 192 y Baena, 2014: 32).

8 «'Yohualli Ehecatl' [...] estaba relacoinado con la capacidad de Tezcatlipoca de estar en todas partes, conocerlo todo y perdonar las faltas» (Sahagún, Libro I, cap. XII, 1999: 32). 
Por otro lado, si interpretamos la escena de manera simbólica -que no literal- la acción en sí es la de una figura derramando la sangre de su sacrificio en un brasero, que actúa a modo de recipiente, del que surge la "explosión de energía creadora" (Boone, 2007: 179). Aunque con algunos matices, el acto en sí, recuerda al mito de creación en el que Quetzalcoatl desciende al inframundo para recoger los preciosos huesos de los antepasados y vierte la sangre de su pene sobre los huesos molidos en el lebrillo de Ciuacoatl, dando lugar a los humanos de maíz. El parecido de las acciones es evidente, pero coincido con Boone (2007: 179-181) en la identificación de esta figura en actitud de sacrificio como Mictlantecuhtli: por la representación esquelética, y por el vínculo que tiene esta deidad con los mitos de creación. No obstante, la presencia de Quetzalcoatl sigue representada gracias a los Ehécatl (no Yohualli Ehécatl) advocados al dios emplumado y la figura entrelazada que sale de la escena.

Este mismo personaje es la que preside la lámina 30 del CB, apareciendo en el centro de la composición. Muchos le han identificado como el alma de Quetzalcoatl identificación que se legitima gracias a los adornos de las colas de los Ehécatl, que son las mismas que las del tocado del dios. Del pico de sendos Ehécatl salen espíritus negros con ofrendas de copal en la mano y además el conjunto está inscrito en un círculo de trenzado vegetal, una trama que varios autores como Anders, Jansen y Reyes García relacionan con el uso de sustancias alucinógenas, habituales en las practicas rituales vinculadas al sacrifico o auto-sacrificio (Anders, Jansen y Reyes García, 1993: 196). La que antes hemos identificado como "rueda negra de conjuros" se transforma ahora en una "rueda de luz" o Chalchihuitl, aunque también se ha interpretado como "el corazón de Quetzalcoatl" (Seler, 1980: 14) - algo comprensible por todas las plumas de Quetzatcoatl-Ehecatl que envuelven el circulo y que además aluden al difrasismo «In quetzalli, in chalchihuitl»; usado para manifestar lo valioso y lo precioso además de hacer referencia al jade y a la vegetación (Baena, 2014: 211). Por otro lado, este elemento aparece pintado de color rojo en el documento original, simbolizando al tonalli ${ }^{9}$ (Klein, 2002: 31-32), elemento que se vuelve a utilizar más adelante en el ritual, aunque de manera más sencilla. Creo necesario dar toda esta importancia a este elemento porque es el que legitima y cohesiona el acto que se estå llevando a cabo en la escena; la creación del tiempo (Boone, 2007: 181-183). Si nos fijamos en los sacerdotes estos aparecen cargando los poderes vegetales o plantas divinas a sus espaldas y llevando en su mano dos objetos íntimamente relacionados con el acto sacrificial: ofrendas de copal y púas de maguey con las que pinchan los cuatro días señalados. Aunque haya quien lo ha interpretado como un ritual de ascenso al poder por la similitud de la acción con la ceremonia de apertura de ojos (Byland, 1993: xxiii-xxiv), creo más elocuente interpretar esta relación como la creación del tiempo (Boone, 2007: 181-183).

A nivel compositivo se mantiene la idea microcosmos dentro del macrocosmos, pero más depurada: la composición es mucho menos caótica. Las esquinas quedan mejor marcadas gracias a los sacerdotes y al hecho del que lleven plantas divinas a sus espaldas, enfatizando aún más la plasmación del axis mundi; se evocan a las cuatro direcciones haciendo alusión a los cuatro postes o árboles que mantienen separados el cielo de la tierra y que marcan los caminos de los dioses (López-Austin, 1994: 19). Por otro lado, tanto en este caso como en la imagen anterior, la acción está ocurriendo dentro de un espacio arquitectónico concreto en el que la materia divina está activa (López-Austin, 1994: 31), es decir, que el muro está encarnando a una deidad. Aunque con diferencias evidentes, como los motivos del interior de los muros, o el tocado de Ciuacoatl -diosa íntimamente relacionada con los mitos de creación-, la organización espacial es la misma, lo único que ha cambiado es el "carácter".

Lo mismo ocurre en la siguiente página (31 CB); nos hallamos aún dentro del "cuerpo de la diosa" pero esta vez nos encontramos con una doble composición simétrica en la misma página. ¿Por qué? Aunque sea tentador pensar que esto simplemente ocurre porque son escenas menores, cabe la posibilidad de que lo que se esté emulando aquí sea algo más que dos escenas inconexas entre sí; en el mito de creación protagonizado por Cipactli (López-Austin, 1999: 18-19) vemos como Quetzalcoatl y Tezcatlipoca descienden del cielo transformados en dos grandes serpientes, para conseguir dividir a la voraz y montuosa criatura marina en dos, creando el cielo y la tierra. Además, cabe recordar que acabamos de ver como se crea el tiempo y por ende el calendario. El Tonalpohualli empieza con Cipactli o día lagarto, y aunque el símbolo en sí aparece en la lámina anterior aquí encontramos dos 
indicios de peso que refuerzan esta relación. (1) Por un lado los días señalados aparecen inseridos en el muro ahora no son parte de la acción son una referencia temporal asociada a un símbolo. Los cuatro símbolos organizan la cuenta de las veintenas en cuatro grupos de 5 días, representando así la totalidad del Tonalpohualli ${ }^{10}$ (Bonne, 2007: 183). (2) Por otro lado los templos son iguales -misma organización espacial, mismo entramado del muro...- pero con pequeñas diferencias duales, como por ejemplo la inversión de los colores del muro o el hecho de que la diosa encarnada por el edificio por primera vez gira la cabeza hacia la derecha. Estos detalles aparentemente sutiles recalcan el carácter dual y simbiótico de la cosmovisión mesoamericana, muy preocupada por relacionar todos los conceptos con su contrario para reflejar que se trata de dos caras de una misma moneda. Otro aspecto que legitima esta interpretación es la aparición de la gran parturienta, sobre todo por mostrarse muerta y por la manera en que el "corazón de Ciuacoatl"11 secciona en dos mitades el cuerpo de la diosa - otro paralelismo con el destino de Cipactli.

Hasta ahora todo el ritual ha ocurrido en un lugar delimitado, cerrado. Un espacio para un público tan selecto como los dioses. En la siguiente escena (32 CB) ya no encontramos la referencia del muro del edificio, estamos en el exterior; el patio ceremonial (Anders, Jansen y Reyes García, 1993: 200). Esto implica un cambio más que significativo en la narrativa del rito: salir al exterior abandonando el edifico espiritado significa el nacimiento de la acción que se ha estado gestando.

No obstante, la composición de la página sigue siendo muy ortogonal: un espacio central flanqueado por 8 parcelas delimitadas por multitud de pedernales de obsidiana - escenario a menudo relacionado con la conocida "Casa de los Cuchillos" que aparece en el Popol Vuh. En el centro, la escena es presidida por el Gran Dios Cuchillo de Pedernal, hijo de Omecíhuatl - parte femenina de la pareja creadora suprema. Al nacer esta deidad fue desterrada del cielo a causa de su aspecto, cayendo sobre Chicomóztoc ${ }^{12}$, donde brotaron de él 1.600 dioses que quedaron igualmente desterrados y viéndose con la misión de bajar al inframundo con el fin de conseguir los huesos o cenizas de los antepasados, custodiados por Mictlantecuhtli, para poder crear hombres que les rindieran culto (Graulich, 2016: 75). Aunque con la expresión facial mucho más hierática e inexpresiva, el Gran Dios aparece en la misma posición de parto que Mictlantecuhtli (29 CB) y que la Gran Parturienta de la página anterior (31 CB). De hecho, también aparece flanqueado por culebras de visión y de su vientre nace un sacerdote advocado a Quetzalcoatl, además de varios Tezcatlipocas que salen de los cuchillos que tiene en las articulaciones. En cada parcela a los márgenes podemos ver a distintos sacerdotes y advocaciones bailando en trance con cabezas de decapitados en sus manos.

En la parte inferior aparece la bautizada como "Diosa Franja" una deidad que en las interpretaciones con enfoque astrológico del rito a menudo se ha apodado como "la de la saya de estrellas", estableciendo la relación entre la diosa y la vía láctea (Milbrath, 1989: 155; y Anders, Jansen y Reyes García, 1993: 178). Pero la mayoría de estudios recientes coinciden en que se trata de un elemento con esencia divina cuya función plástica es básicamente la de separar los episodios del ritual y servir a modo de transición entre ritos. De ella surgen dos cuchillos de pedernal que recuerdan a la misma cabeza del Gran Dios Cuchillo de Pedernal de entre los que sale un sacerdote advocado a Quetzalcoatl; que presidirå la siguiente fase del ritual.

\section{Rito 2}

Como hemos podido comprobar todas las escenas posteriores a la página 30 - la creación del tiempo - tienen referencias temporales inseridas en la composición pero a partir de la 33 dejamos de tener esta referencia hasta la lámina 39, donde empieza el tercer "episodio". Esto implica que la cadencia narrativa del rito sufre una alteración. Si solo se hubiera tratado de esta página y la siguiente aún se podría argumentar que ambas escenas son homónimas y por tanto persiguen el mismo fin: el de presentar un nuevo escenario dejando claro la naturaleza de cada uno de los sitios. Por este motivo se podría entender y hasta justificar la ausencia de referencias temporales - la acción se presenta en forma de imagen, como una fotografía de la esencia del sitio. Sin embargo, en la página 35 ya deberíamos volver a encontrar referencias temporales pero esto no ocurre de manera explícita pese a haber recursos compositivos sencillos ya planteados para insertar los días en la imagen. Aun así,

10 Calendario ritual dividido en 20 semanas de 13 días.

11 Elemento situado en el abdomen de la diosa en la escena superior de la página 31 del CB.

12 'Lugar de siete cuevas', lugar de origen de las siete tribus nahuas. 
encontraremos elementos que además implican la presencia del factor tiempo a la vez que evidencian la existencia de una narrativa ritual, como la ruta representada en las láminas 35, 36, 37 y 38 del CB.

Si analizamos compositivamente las láminas 33 y 34 del CB podemos ver como ambos templos del cielo se presentan de perfil, orientados a la izquierda - algo que de entrada ya sorprende porque lo más habitual seria que aparecieran encarados, orientados cada uno hacia un lado - tal y como veremos en la página 37.

Este es el llamado "Templo de la Serpiente Negra" o "Templo Negro", un templo con la cubierta cónica en la que habitan los poderes del fuego o de los guerreros muertos, coronada por un cuchillo de pedernal con la cara de un sacerdote (Anders, Jansen y Reyes García, 1993: 204). De ahí surgen: por un lado el hilo de la araña Tecuantocatl (araña venenosa), del que cuelgan varios elementos relacionados con el sacrificio; y por el otro lado la serpiente que baja enroscada en todo el edificio hasta la base, donde aparece con las fauces abiertas en una postura poco relajada. Prácticamente todos los personajes que aparecen en escena están tomando parte activa en un ritual de sacrificio: delante del templo Quetzalcoatl y Venus realizan una doble cardioectomía ${ }^{13}$ a uno de los sacerdotes de la página 30 -creación del tiempoasistidos por una sacerdotisa de la página 31; en la entrada del templo encontramos dos personajes preparados para ser sacrificados señalados con conchas - el que está encima de la rueda de sacrificios cubierto por una tela sagrada es Xipe Tótec o Tezcatlipoca Rojo. Dentro del edifico Venus aparece en actitud reverencial frente a Quetzalcoatl, quien está realizando una punción bucal.

Con respecto a los cuerpos desarticulados de la escalera hay pocos autores que los mencionen pero si pasamos al "Templo de la Serpiente Roja" o "Templo Rojo" (34 CB) vemos que hay dos personajes en el mismo sitio y con la misma postura pero con una diferencia sustancial; en sus manos llevan ofrendas de copal y púas de maguey, símbolos por antonomasia del sacrificio. Sin embargo en ambos casos los sacrificados aparecen con los ojos abiertos, como símbolo de la energía vital de la que sus cuerpos eran poseedores. Al representarlos de éste modo se está haciendo hincapié en el objetivo fundamental del sacrifico; traspasar ésta energía al plano divino.

Como podemos apreciar, las escenas son completamente homónimas, aunque con pequeñas variaciones.
En este caso se han sustituido los objetos que colgaban del hilo de Tecuantocatl por otras 5 arañas como Ciuateteoh, vinculada con las mujeres que mueren durante el parto. Se trata de una alusión a la diosa madre Ciuacoatl reiterada también por los espíritus de las mujeres esqueléticas con garras que sustituyen a los guerreros muertos (33 CB). De hecho tiene mucho sentido encontrar alusiones a esta diosa: (1) Por un lado Ciuacoatl es una diosa guerrera y amante de los guerreros - los mismos que encontramos en la cubierta del templo de la lámina 33. (2) Ciuacoatl es también conocida por ser la protectora y recolectora de almas de las mujeres fallecidas al dar a luz - lo cual explicaría la postura descoyuntada de las $10 \mathrm{fi-}$ guras. Además tenemos el antecedente de la página 31, en la que aparece la Gran parturienta muerta dando a luz a varios espíritus negros. (3) Además, estas figuras aparecen en el tejado y Ciuacoatl también es conocida como "la de la saya de estrellas", es decir que en cierto modo se estã representando una bóveda celeste nocturna.

Como ya he comentado los juegos de contrarios y la dualidad son uno de los mayores pilares de la cosmovisión mesoamericana y estos dos Templos del Cielo no son una excepción. De hecho son una alusión obvia a los "Templos del Cielo" de Ometechutli y Omecíhuatl -pareja creadora suprema- al representar la oposición complementaria que comentaba (López-Austin, 1999: 9-10;y Graulich, 2016: 67). Además, es inevitable no pensar en el mito de Quetzalcoatl, Tezcatlipoca y Cipactli, dado que en ambos casos aparece una serpiente enroscada en el templo, que representaría al monstruo lagarto.

Delante de la entrada del templo vemos a Tonacatecuhtli -Señor del sustento, la creación y la fertilidad- recostado en la rueda de sacrificios, mientras un espiritado con el cuerpo pintado de negro está encendiendo un nuevo fuego en su pecho, en el que aparece el símbolo del Tonalli - recordando el calor del sol, lo precioso y lo valioso. Del humo que se desprende aparece un espíritu rojo, color del documento original, que entra volando en el templo, donde se convertirå en el nuevo Sol encarnado por Xolotl Rojo (Bonne, 2007: 189).

Acabada la presentación del sitio volvemos a la acción y lo primero que vemos es como la sangre del auto-sacrificio por punción de pene de Quetzalcoatl se derrama hacia las cuatro direcciones -recuerdo del axis mundi-, en las que encontramos a Yoaltecuhtli, señor de la noche, en los colores direccionales (Bonne, 2007: 192). El mismo

13 Sacrificio ritual que consiste en realizar una incisión entre la tercera y la cuarta costilla con un cuchillo de pedernal y extraer el corazón por dicho orificio para ofrendarlo a los dioses como símbolo y motor de la energía vital. 
dios es el que aparece en el templo, ahora representado como un lugar lúgubre, custodiando el Bulto Sagrado ${ }^{14,15}$ - el gran protagonista de este episodio. Justo enfrente encontramos a los hermanos Quetzalcoatl y Tezcatlipoca delante del templo quienes después de la penitencia piden que se les entregue el Bulto, y, tras la entrega, empiezan el itinerario a través del patio ceremonial. Tezcatlipoca, armado como guerrero escolta al dios emplumado quien carga el Bulto a su espalda, dejándole las manos libres para llevar púas de maguey y ofrendas de copal. Cabe hacer hincapié en la manera en que se ha representado la ruta de estos personajes: las líneas rectangulares azules -color del documento original- con pisadas actúan a modo de guion gráfico o soryboard, lo cual implica una manera muy concreta de desplazarse por el espacio sagrado. En otras palabras, el detallismo y precisión de personajes, objetos y acciones representados de manera tan específica es un argumento de peso para entender estas páginas podrían ser un guion litúrgico.

Durante el recorrido pasan al lado de los lugares del Anciano Cipactonal. En ambos casos aparece vistiendo la piel de un monstruo con espinas en los brazos -posiblemente la piel de Cipactli- y con un gran tonalli rojo -color del documento original- en el torso. A la izquierda le vemos en un lugar oscuro y tenebroso con ofrendas de copal y púas de maguey en la mano; y a la derecha aparece arbitrando un partido ritual de juego de pelota entre un sacerdote advocado a Yoaltecuhtli y otro advocado a "Ojo Rayado" o "Stripe Eye", manifestación de Quetzalcoatl (Bonne, 2007: 190).

Cuando Quetzalcoatl y Tezcatlipoca llegan a su destino se coloca el Bulto Sagrado en el centro del patio, o al menos aparece en el medio de la composición, y se abre, liberando una explosión de energía aún más poderosa que la representada en la página 29 del CB. Los Yohualli Ehécatl se expanden más exuberantes llevando en su pico elementos esenciales para la vida y el ritual como; maíz, maguey, malinalli, hierbas, sangre, agua, etc. (Bonne, 2007: 190). De los mismos picos abiertos salen espíritus de obsidiana con sombreros cónicos. Durante la explosión de energía el Bulto Sagrado también libera una Serpiente Remolino Oscura que envuelve la escena desde el centro hacia la derecha hasta caer por el lado izquierdo de las páginas 36 y 37 del CB hasta llegar a la 38. Por su interior viaja 0jo Rayado, junto con otros objetos ceremoniales como flautas, discos, flechas y también mariposas y águilas. A nivel compositivo, recordando a la anterior explosión de energía, se retoma la idea de circulo inscrito en un cuadrado ${ }^{16}$, es decir el microcosmos dentro del macrocosmos.

Me gustaría hacer un pequeño apunte sobre las mariposas representadas dentro de la Serpiente Remolino Oscura en las páginas 36 y 37 del CB. Estas son las dos unicas mariposas que aparecen representadas en la parte central del CB y entre ellas no parecen presentar demasiadas similitudes iconograficas. Esto puede deberse a que se estén representando a la mariposa diurna y a la mariposa nocturna, un motivo recurrente en los tejidos mesoamericanos (Bargalló, 2009: 146-148). Así mismo éstas mariposas recuerdan bastante a las representadas en los pectorales de los Atlantes de Tula, en Tollan-Xicocotitlan.

Hasta ahora hemos podido leer la imagen siguiendo una lectura lineal "sencilla", pero con el elemento de la Serpiente Remolino Oscura este orden de lectura deja de aplicarse; la narrativa salta de la página 36 a la 38 directamente cuando Ojo Rayado sale a escena por la boca de la serpiente, despertando así del trance. Bonne (2007: 192) relaciona este viaje con el momento en que Quetzalcoatl viaja al inframundo para conseguir los huesos de los antepasados en poder de Mictlántecuhtli.

Justo en frente encontramos a Tláloc vistiendo la piel de un cocodrilo en el borde de una piscina ceremonial, aunque también podría tratarse de un río (Anders, Jansen y Reyes García, 1993: 215; y Bonne, 2007: 192). Un espíritu esquelético compatible con el agua y los árboles cae dentro mientras diferentes plantas y árboles brotan de su oreja, cabeza, boca y pie. Al mismo tiempo éste personaje propina un golpe con el bastón curvo de Quetzalcoatl a la mandíbula de Tláloc, quién escupe un chorretón de sangre - que servirá para nutrir el río. La escena puede entenderse como la forma en que la lluvia ayuda a mantener las reservas de agua y a alimentar las plantas y árboles (Bonne, 2007: 192-194).

En la parte inferior de la lámina (38 CB), a la derecha de la charca, un sacerdote advocado a Tláloc (Bonne,

14 Para más información sobre los Bultos Sagrados o Rituales consultar Ayala (2002).

15 Identificación establecida por Anders, Jansen y Reyes García (1993: 175).

16 Aunque no sea tan obvio como en el caso de las páginas 29 y 30 del CB, la Serpiente Remolino Oscura deja clara la actitud de contener y circundar esta explosión por la contundencia y protagonismo que adquiere la serpiente al desplegarse, casi dejando en segundo plano la explosión más grande que ha ocurrido en el ritual. 
2007: 194) sujeta un objeto que ha sido a menudo identificado como "cáliz precioso" (Anders Jansen y Reyes García, 1993: 217). Si observamos el objeto y lo comparamos con cualquier incensario precolombino de la zona mesoamericana salta a la vista que no se trata de un cáliz sino de un incensario ritual. De este surge un humo que al entrar en contacto con un personaje con el maquillaje de Ojo Rayado hace aparecer una serpiente de visión que reconduce la acción hasta la página 37 del CB. Allí el sacerdote se coloca entre los templos del cielo encarado hacia el templo de las llamas y los rayos -templo de cubierta cónica- en el que se encuentra Xolotl, a quien ofrenda el incensario. Encarado al templo cónico se sitúa el templo de orejas o Templo del cielo, del jade y las flores preciosas (Anders, Jansen y Reyes García, 1993: 216), en el interior del cual se encuentra el Nuevo Sol tocando una flauta y un tambor. Junto con Tláloc delante del templo cónico está la sacerdotisa Xoxhiquetzal - flor preciosa o hermosa - ofreciendo pulque (Anders Jansen y Reyes García, 1993: 217).

Acto seguido Xolotl desciende del templo hacia un altar precioso situado encima de una cueva. Allí es donde se crean los rayos, lanzando un rayo con una serpiente de fuego (Bonne, 2007: 195). El dios aparece flanqueado por una pareja de espíritus de cuchillos de obsidiana y mujeres portadoras de las telas sagradas. A lado y lado de la escena hay cuatro espíritus del rayo, cada uno advocado a una dirección, otro ejemplo que ayuda a recalcar y tener presente la importancia de la cosmovisión y el axis mundi mesoamericanos. De hecho las referencias direccionales a nivel compositivo y narrativo son casi constantes; las encontramos en las páginas $29,30,31,32,33,35$ y 37 del CB - aunque en la página 36 del CB pueda parecer que se está aludiendo al axis mundi no es así porque los cuatro puntos cardinales no quedan marcados de manera suficientemente explícita, algo crucial para el esquema representativo en cuestión.

Tras haber creado el rayo Xolotl marcha a un altar delante del cual se encuentran prisioneros con las manos atadas a la espalda y cubiertos con mantas ceremoniales con conchas ${ }^{17}$, lo cual nos indica que se tratan de prisioneros a preparados para ser sacrificados ritualmente. Los cuatro ejemplares están siendo custodiados por los ancianos Oxomoco y Cipactonal ${ }^{18}$.
Justo debajo encontramos a los progenitores del primer humano, quienes aparecen en pleno acto de copulación dentro del recinto cuadrado del jade supuestamente encharcado de sangre - aparece de color rojo en el documento original. La identificación de éstos personajes sigue indeterminada; se cree que la parte masculina podría ser Tonacatecuhtli, Cipactonal o Tepeyollotl y Tonacacihuatl, Oxomoco o Chalchiuhtlicue para la parte femenina (Boone, 2007: 195).

En el centro de esta pequeña composición encontramos un tonalli del que surge un personaje con distintas interpretaciones. Por las mazorcas de maíz que lo flanquean Anders, Jansen y Reyes García (1993: 221) propusieron que se tratara del Joven del Maíz. Sin embargo por la misma razón Tabue (1986: 62) y Bonne (2007: 195) sugieren que se trata de una representación simbólica de la creación del hombre. Personalmente ambas interpretaciones me parecen plausibles, de hecho ambas interpretaciones casan con el mito de Quetzalcoatl en su misión por conseguir los huesos de los antepasados y crear la humanidad explicado anteriormente (Bonne, 2007: 195). Con esto se termina el segundo rito del ritual, que sigue en la página 39 encabezado otra vez por la "Diosa Franja" a modo de separador.

\section{Conclusiones}

Cabe decir que las verdaderas conclusiones del estudio realizado se publicaran en la última entrega de esta serie de artículos, ya que considero que hasta que no se haya analizado la totalidad del ritual no es aconsejable emitir un juicio al respecto. Sin embargo resulta evidente que hay un nexo muy fuerte entre el documento, la cosmovisión y la mitología, sobre todo con los mitos de creación del universo. Son constantes las referencias direccionales y las adaptaciones de la representación del axis mundi mesoamericano, además de que los principales personajes son divinidades estrechamente relacionadas con los mitos de creación.

Por otro lado es obvio que se está siguiendo una narrativa, de hecho las láminas en sí mismo lo son. Muestran detalladamente todos los personajes, objetos, acciones y lugares que aparecen, incluso dando referencias temporales a las escenas del rito. De hecho creo que el documento podría ser algo así como un guion litúrgico gráfico, posiblemente ligado a un espacio ceremonial concreto.

17 Las mantas son iguales que acompañan a las víctimas de sacrificio en las láminas 31 y 33 del CB.

18 Esta pareja dual constituye el tiempo y por ello está muy relacoinada con el calendario. También representan los pueblos antiguos cuyos huesos acabará robando Quetzalcoatl. 


\section{Bibliografía específica}

ANDERS, F.; JANSEN, M.; Y REYES GARCÍA, L., 1993. Los templos del Cielo y de la Oscuridad. Oráculos y liturgia. Libro explicativo del llamado Códice Borgia. Fondo de Cultura Económica, México.

BAENA RAMÍREZ, A., 2014. Metáforas, metonímias Metáforas, metonimias y disgrafismos en la parte central del Códice Borgia (29-32). En Itinerarios, vol. 20, pp. 200-224. Instituto de Estudios Ibéricos e Iberoamericanos, Universidad de Varsovia, Varsovia.

BATALLA ROSADO, J. J., 2008. Los códices mesoamericanos: métodos de estudio. En Itinerarios, vol. 8, pp. 43-65. Instituto de Estudios Ibéricos e Iberoamericanos, Universidad de Varsovia, Varsovia.

BOONE, E. H., 2007. Cycles of time and meaning in the Mexican books of fate. University of Texas Press, Austin.

BYLAND, B.E., 1993. Introduction and Commentary. En The Codex Borgia: A Full-Color Restoration of the Ancient Mexican Manuscript, G. Díaz y A. Rodgers (eds). Dover Publications, Mineola.

MILBRATH, S., 1989. A Seasonal Calendar with Venus Periods in Borgia 29-46. En The Imagination of Matter: Religion and Ecology in Mesoamerican Traditions, D. Carrasco (ed). British Archaeological Reports, Oxford.

NOWOTNY, K.A., 1961. Tlacuilolli. Die Mexikanischen Bilderhandschriften Stil und inhalt mit einem Katalog Der CodexBorgia-Gruppe. Gebr. Mann Verlag, Berlin.

NOWOTNY, K.A., 1976. Codex Borgia. Akademische Druck Und Verlagsanstalt, Graz.

NOWOTNY, K.A., 2005. Tlacuilolli. Style and Contents of the Mexican Pictorial Manuscripts with a Catalog of the Borgia Group. Traducción y edición de G.A. Everett, Jr., and E.B. Sisson. University of Oklahoma Press, Norman.

SELER, E., 1906. Codex Borgia. Eine altmexikanische Bilderschrift der Bibliothek der Congregatio de Propaganda Fide, Band II. Gebr. Unger, Berlin.

SELER, E., 1963. Comentarios al Códice Borgia. Traducción de M. Frenk. Fondo de Cultura Económica, México.

\section{Bibliografia general}

AYALA, M., 2002. El bulto ritual de Mundo Perdido, Tikal. Universidad Nacional Autónoma de México, México.

BARGALLÓ, M., 2009. Las mantas, instrumentos de los dioses. Propuesta de reconstrucción de ocho mantas mexicas partiendo de las instrucciones del Códice Florentino. En Actas. IV Jornadas internacionales sobre textiles precolombinos, V. Solanilla (Ed.). Grup d'Estudis Precolombins, Barcelona.

GRAULICH, M., 2016. El sacrificio humano entre los Aztecas. Fondo de Cultura Económica, México.

KLEIN, C., 2002. La iconografía y el arte mesoamericano. En Arqueología mexicana, vol. 55, pp. 28-35. Editorial Raíces, México.

LÓPEZ-AUSTIN, A., 1994. Tamoachan, Tlalocan. Fondo de Cultura Económica, México.

SAHAGÚN, F.B., 1999. Historia general de las cosas de la Nueva España. Editorial Porrúa, México.

TABUE, K. A., 1986. The Teotihuacan Cave of Origin: The Iconography and Architecture of Emergence Mythology in Mesoamerica and the American Southwest. En Anthropology and Aesthetics, vol. 12, pp. 51-82. 


\section{Material gráfico de apoyo}

Las siguientes imágenes fueron extraídas de la publicación de Bonne (2007) y editadas por Terry Sucrana a partir de mis estudios.

Conjunto 1. Rito 1: páginas 29, 30, 31 y 32 del CB con la identificación de personajes, objetos y elementos principales.
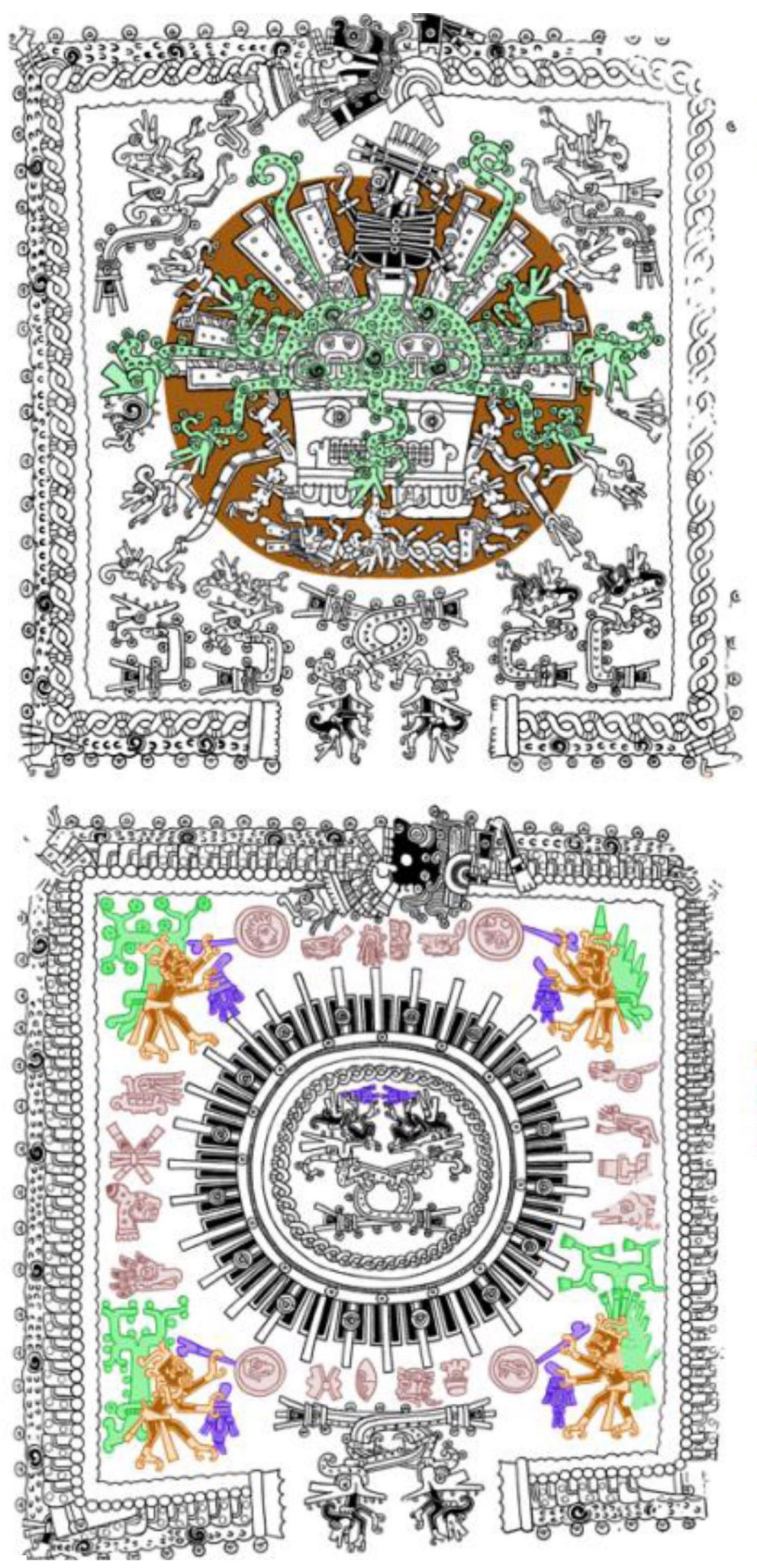

Página 29

Rueda negra de conjuros

Yohualli Ehécatl

Chalchiuhxicalli

Mictlantecuhtli

Soga de peniténcia

Ehécatl (Quetzalcoatl)

Templo espiritado (Ciuacoatl)

Página 30

Quetzalcoatl (Alma de)

Espiritus negros con ofrenda de copal

Chalchihuitl

Sacerdotes

Poderes vegetales

Dias 


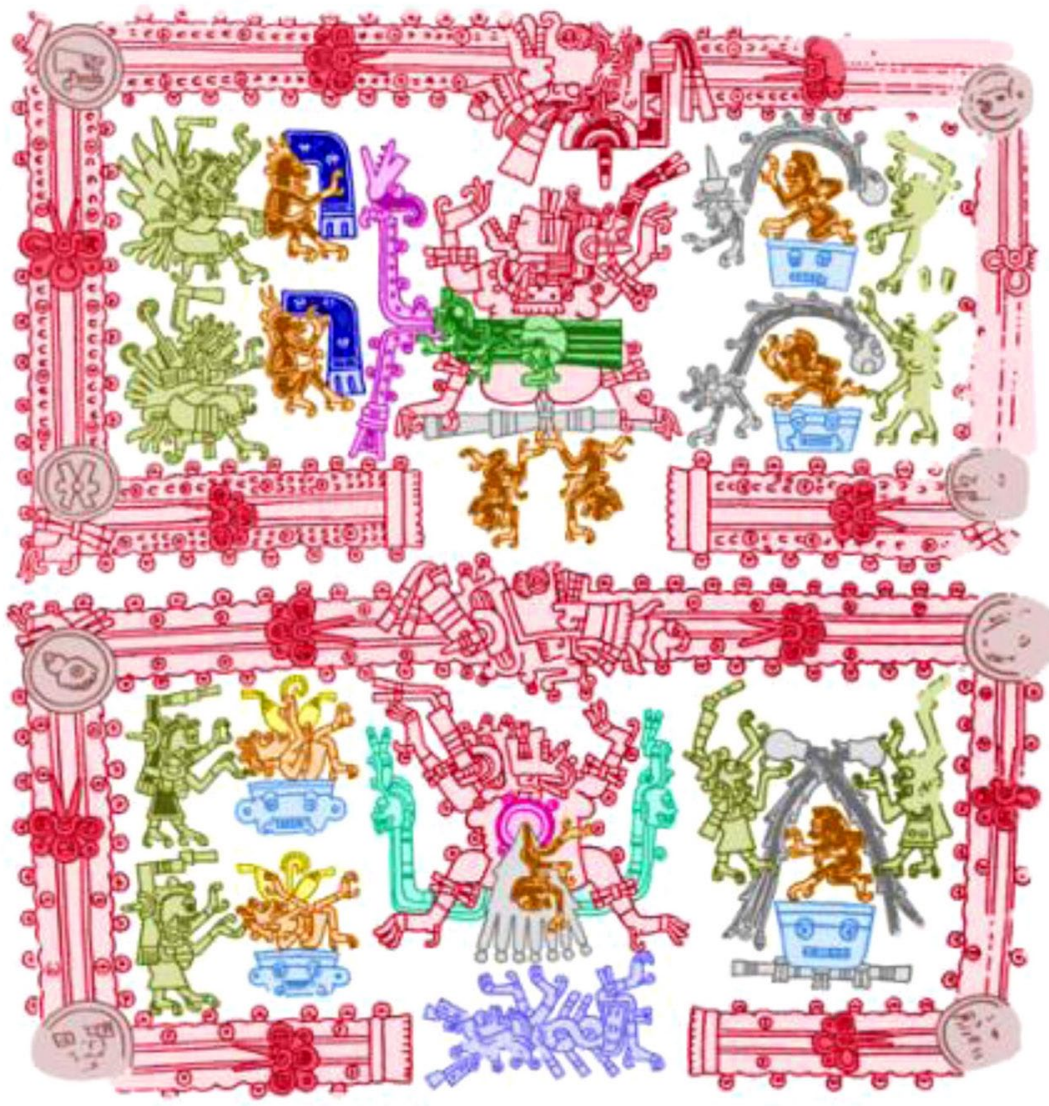

Página 31

Dias señalados

- Alma Quetzalcoatl

Sacerdotisas de Ciuacoatl

Telas sagradas

Braseros espiritados

Espiritus negros

Maiz

- Corazón de Ciuacoatl

Culebras preciosas

Diosa Muerte

Tonalli

Liquido oscuro (Bebida divina)

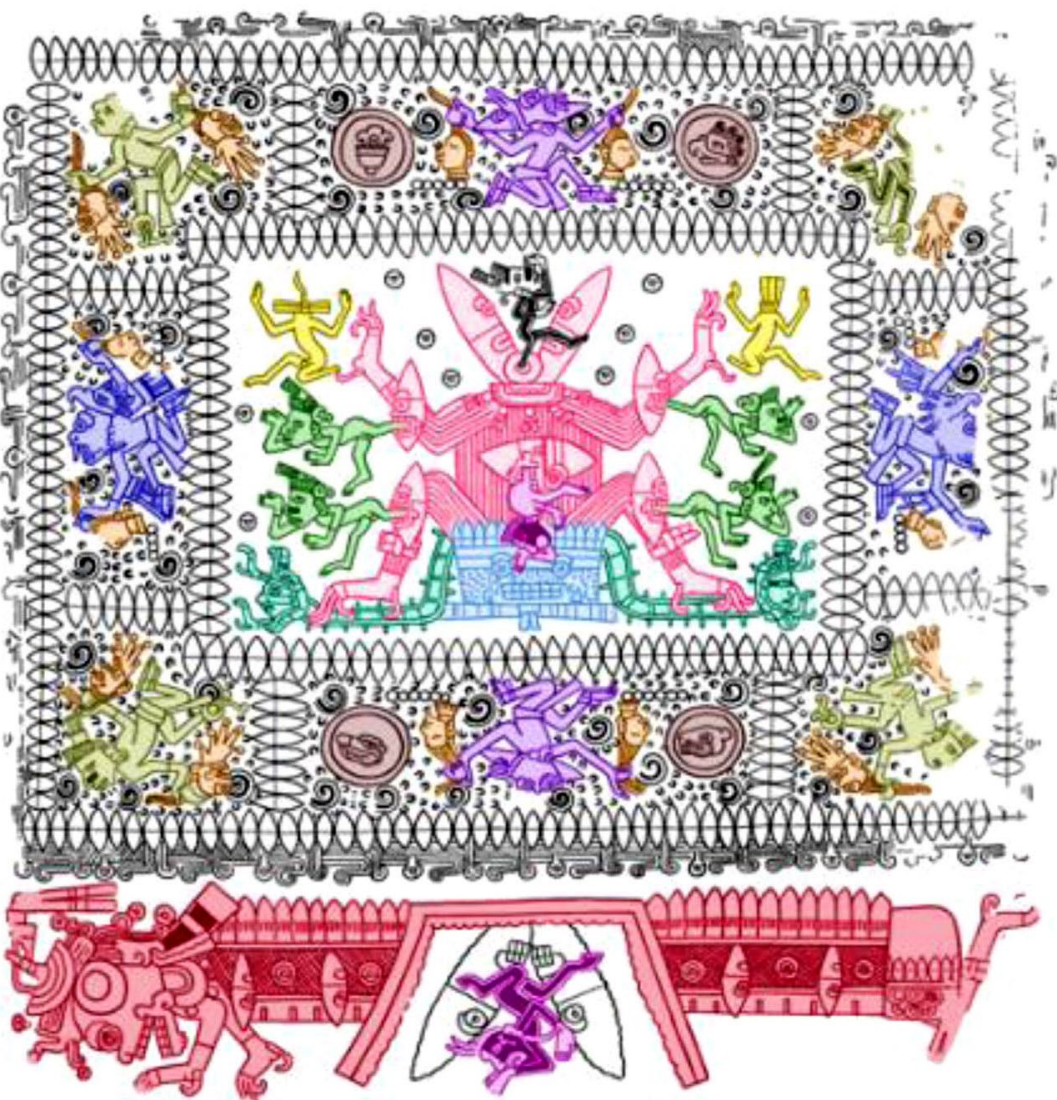

Página 32

Gran Dios Cuchillo Pedernal

Culebras de visión

Sacerdote Quetzalcoatl

Tezcatlipocas

Sacerdotes Divina Águila

Sacerdotes Divino Cuchillo

Sacerdotes Tezcatlipocas

Cabeza decapitadas

Decapitados

Dias señalados

Diosa Franja

Brasero espiritado 
Conjunto 2. Rito 2: páginas 33 y 34 del CB con la identificación de personajes, objetos y elementos principales.
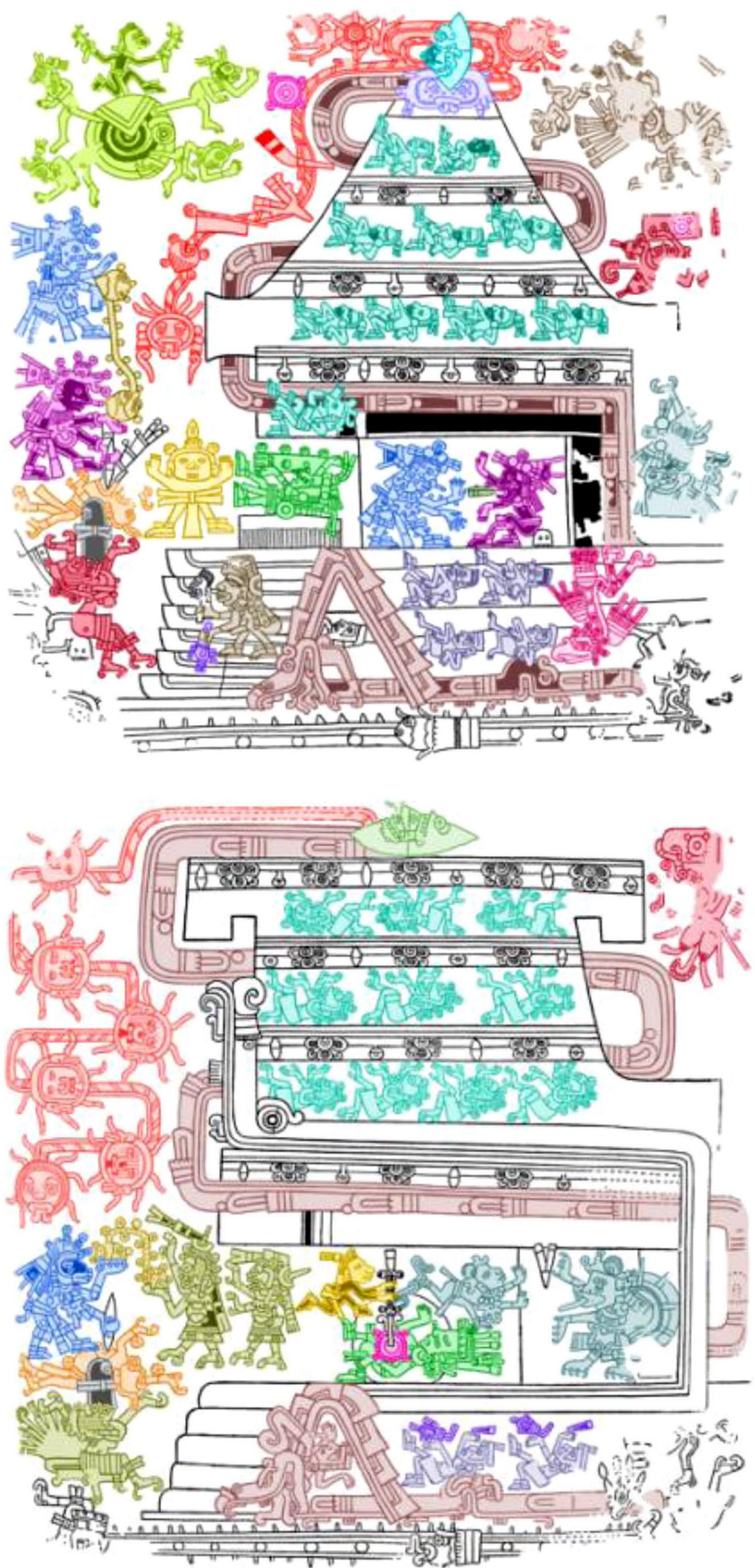

Página 33

Espiritados pelota de goma

Tecuantocatl e hilo (Araña)

Chalchihuitl

Cuchillo de pedernal con rostro de sacerdote

Poderes del fuego / Guerreros muertos

Sacerdote negro encendiendo fuego en el pecho de un dios

Sacerdotisa Ciuacoatl floreciendo como maiz

Xolotl

Dios Venus

Quetzalcoatl

Doble corazón

Sacerdote (pg. 30)

Serpienta negra

- Xipe Tótec / Texcatlipoca Rojo

Victimas de sacraficio

Águila

Sacerdote del Fuego

Ofrendas de copal

Púa

\section{Página 34}

Arañas

Cuchillo con el rostro de un sacerdote

Ciuacoatl floreciendo como maiz

Mujer esquelética con garras

Serpiente Roja

Xolotl negro

Sacerdote (pg.30)

Sacerdotisas Ciuacoatl

Doble corazón

Tonacatecuhtli

Sacerdote negro

Xolotl rojo

Ofrendas de copal

Victimas de sacrificio

Tonalli 
Conjunto 3. Rito 2: páginas 35 y 36 del CB con la identificación de personajes, objetos y elementos principales.

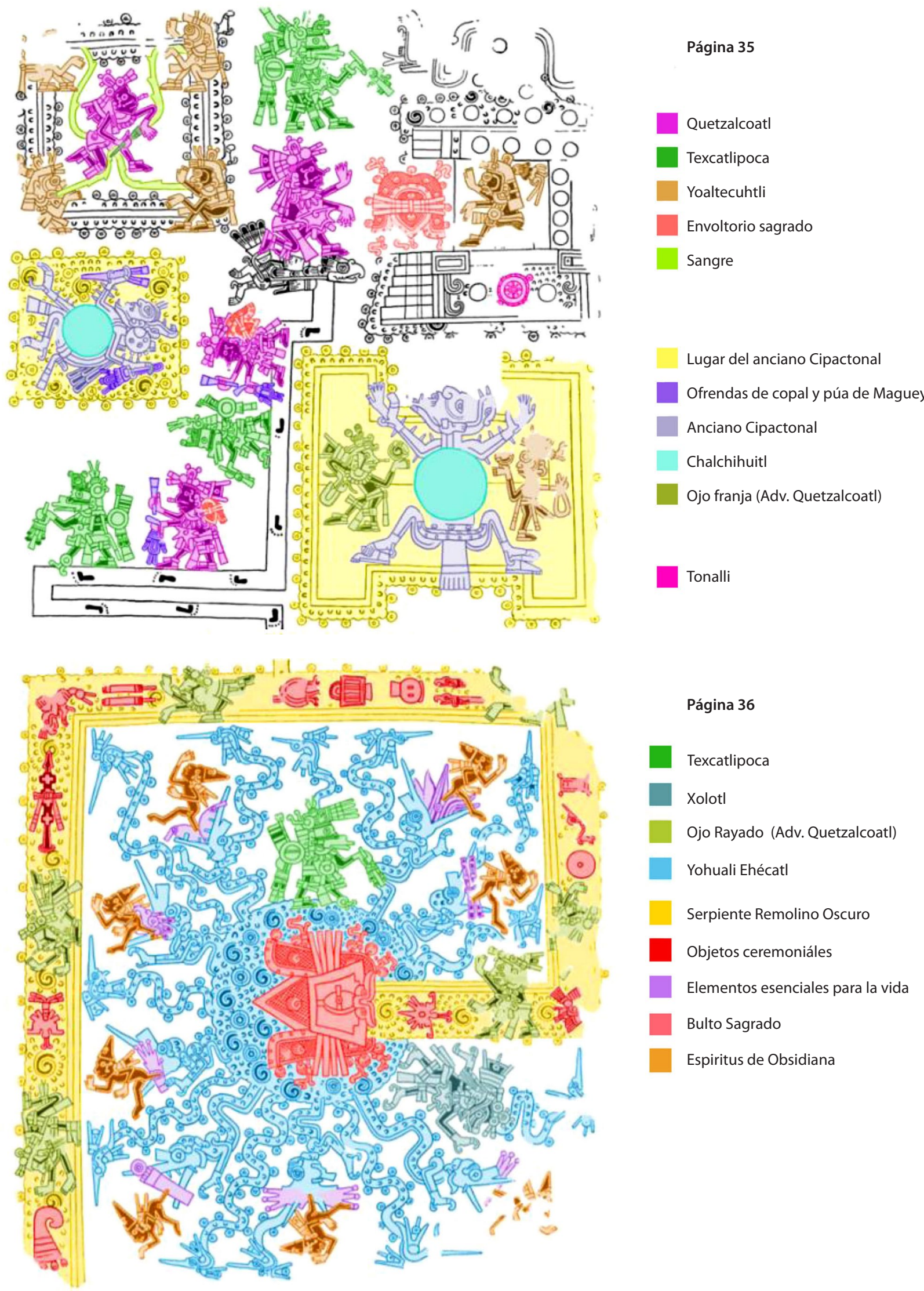


Conjunto 4. Rito 2: páginas 37 y 38 del CB con la identificación de personajes, objetos y elementos principales.

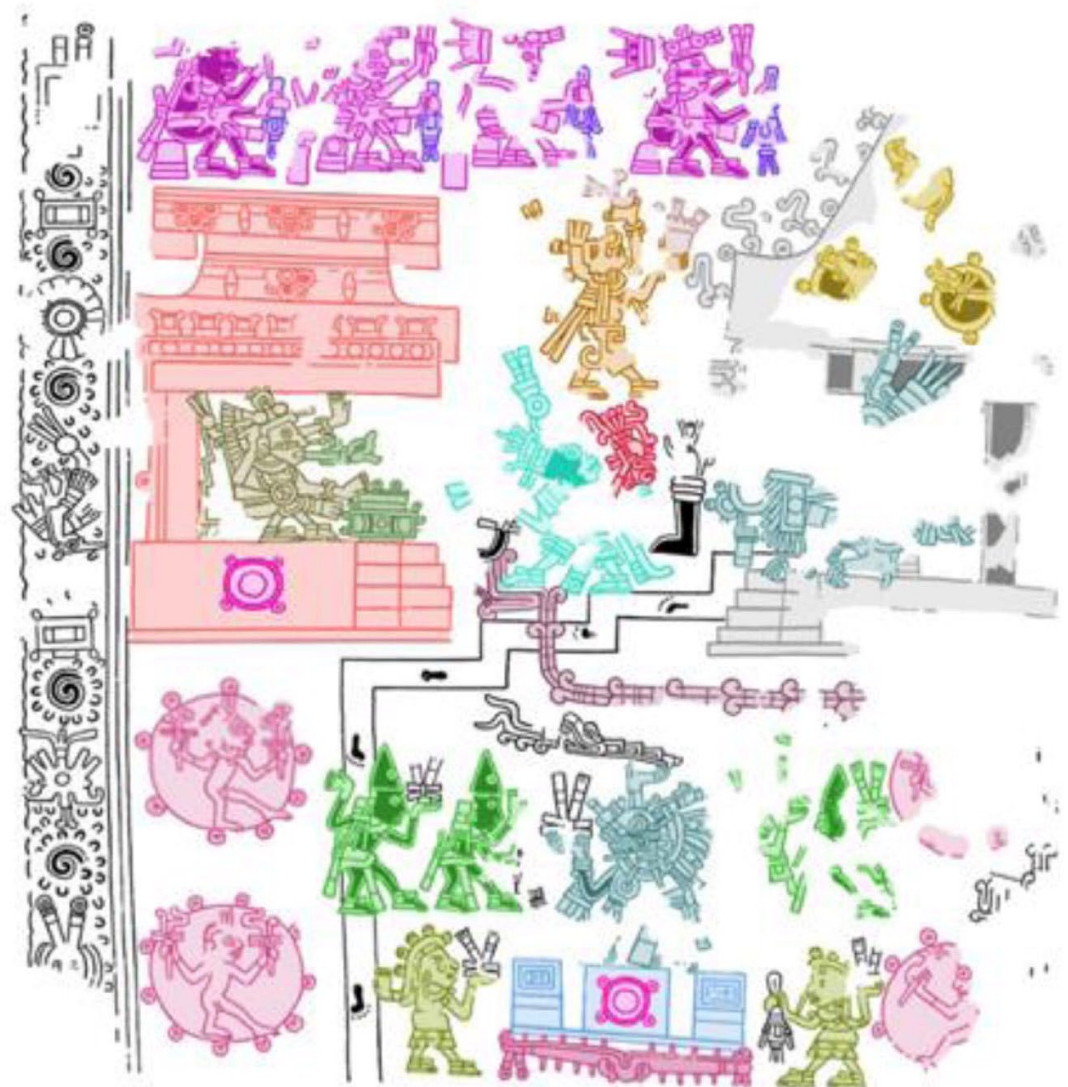

Página 37
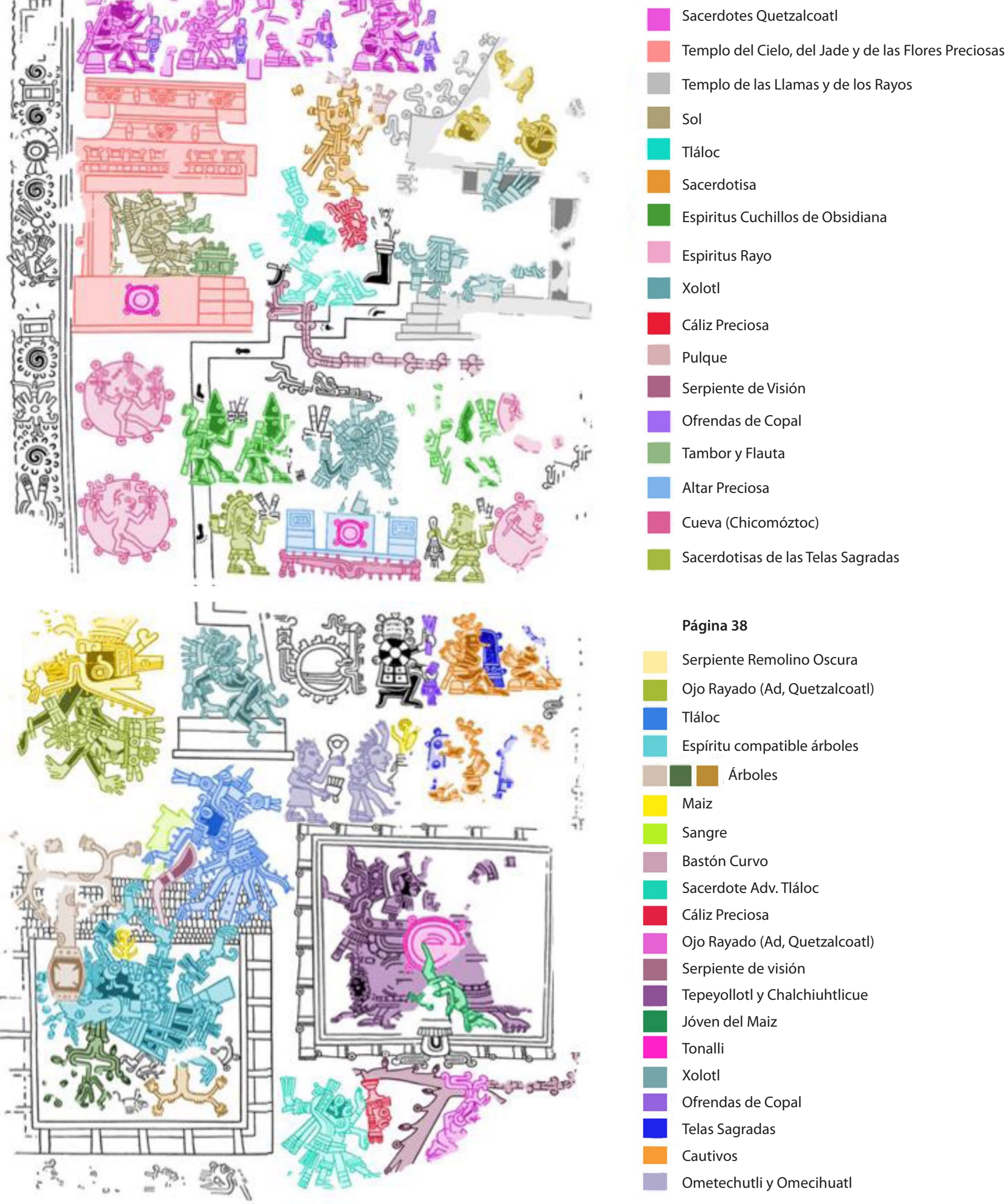

Página 38

Serpiente Remolino Oscura

Ojo Rayado (Ad, Quetzalcoatl)

Tláloc

Espíritu compatible árboles

Árboles

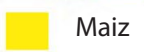

Sangre

Bastón Curvo

Sacerdote Adv. Tláloc

Cáliz Preciosa

Ojo Rayado (Ad, Quetzalcoatl)

Serpiente de visión

Tepeyollotl y Chalchiuhtlicue

Jóven del Maiz

Tonalli

Xolotl

Ofrendas de Copal

Telas Sagradas

Cautivos

Ometechutli y Omecihuatl 